\title{
Papers
}

\section{Efficiency and effectiveness considerations in determining strategic and operational paths to ebusiness enablement}

Received: 19th May, 2006

\section{Bruce E. Perrott}

is Director of Post Graduate Programs and Research Director with the Marketing Strategy and Technology Group at the School of Marketing, University of Technology, Sydney. Dr Perrott is involved in the area of strategic management. He is concerned with how business and marketing strategies are formulated, formalised and managed through to the implementation phase. The interest in strategic management is pursued through a broad range of activities including post graduate course design and teaching, consulting, mentoring, research, management training and development.

$\mathrm{He}$ is also a strategy and marketing consultant with a focus on viable practice, advising senior managers on business and marketing strategies for growth. He has worked internationally with both public and private sector organisations such as the United Nations (UNCTAD), American Express, Lend Lease, CISCO, Wespac, Fuji Xerox, HCF, Federal Airports Corporation, AT \& T, Transgrid, Civil Aviation Authority and the Australian Tourist Commission.

Prior to his academic and consulting careers, he held senior marketing management positions in the food, finance, petroleum and insurance industries. He was located in Sydney and London with American, British and Australian companies.

Bruce E. Perrott

University of Technology,

Sydney

School of Marketing

PO Box 123 Broadway,

NSW 2007,

Australia

Tel: 0295143524

Fax: 0295143535

e-mail:

Bruce.Perrott@uts.edu.au

Abstract Shareholder, competitor and consumer pressures have motivated organisations to embrace various aspects of electronic business for the purposes of efficiency and effectiveness. The complex and rapidly changing montage of emerging and converging technologies, which together make up ebusiness capability at any point in time, inhibit the crystallisation of a clear model for managers to use. As electronic connections between customers and suppliers increase in frequency and complexity, research in this area is becoming increasingly important in an effort to better understand the impact electronic networks have on buyer-seller relationships and business networks. This paper examines recent exploratory research carried out with senior managers in the Australian telecommunications and banking industries in an effort to better understand perceptions of the impact of ebusiness developments on the effectiveness and efficiency of those industries and organisations at a point in time. Research findings are used as a basis for developing prescriptive guidelines. These guidelines take the form of a matrix, which is intended to guide the efforts for developing ebusiness capability according to strategic or operational initiatives.

\section{ELECTRONIC NETWORKS}

Electronic commerce (EC) is about the exchange of digitised information between parties. This may represent communication between two parties, co-ordination of the flow of goods and services or the transmission of electronic orders. ${ }^{1}$

If electronic commerce relates to transactions, electronic business 
(ebusiness, or EB) takes a more holistic perspective with this definition; 'Any Internet initiative (Tactical or strategic) that transforms business relationships, whether those relationships be business to consumer, business to business, intra business or even consumer to consumer. ${ }^{2}$ Moving beyond the internet, a broader definition of ebusiness has been suggested by Laudon and Traver': 'The digital enablement of transactions and processes within a firm, involving information systems under the control of the firm.'

Advancements in and convergence of the technologies of electronic networks have provided firms with incentives to use these channels as communications and distribution conduits in their dealings with other businesses

(business-to-business) and the end consumer (business-to-consumer). The value of electronic business-to-business transactions in 2001 was estimated at US $\$ 700 \mathrm{bn}$, with business exchanges of all kinds estimated at US $\$ 12$ trillion. By contrast, the business-to-consumer transactions estimates were much smaller at US\$65 bn. ${ }^{4}$ In 2006, total online shopping and $\mathrm{B} 2 \mathrm{~B}$ transactions in the USA alone are estimated to be in the range of $\$ 3-7$ trillion (Turban et al. 2006). ${ }^{5}$

Shareholder, competitor and consumer pressures have motivated organisations to embrace various aspects of electronic business for the purposes of efficiency and effectiveness. The nature and rate of adoption of the emerging ebusiness technologies and strategies will be of considerable interest to managers, who will be progressively looking to improve operating efficiency and effectiveness in marketing networks as well as in communications and distribution channels, which together make up vital supply chains. ${ }^{6}$

This paper examines some recent exploratory research carried out with senior managers in the Australian telecommunications and banking industries in an effort to better understand perceptions of the impact of ebusiness developments on the effectiveness and efficiency of their industries and organisations at a point in time (Perrott 2001). ${ }^{7}$

Telecommunications companies where chosen because of the key role they play in providing capability and connectivity to potential EB users; hence senior managers in these companies should have an understanding of current EB issues.

Banking companies where chosen because of the high potential benefits that could be gained from ebusiness strategies. Electronic banking has superior cost and marketing advantages over traditional branch banking networks. It was therefore considered that senior bank managers would be very conscious of the issues surrounding the adoption of ebusiness strategies.

\section{RESEARCH METHODOLOGY}

As the research objective was to uncover managers' perceptions of issues relating to the development of electronic business and networks, qualitative research methodology was used. The research approach was through semi-structured in-depth interviews of about one hour's duration. Senior managers in the selected companies were chosen on the basis of the likely effect of $\mathrm{EB}$ on their functional responsibilities. One or two researchers were present at each interview to gather data via note taking and audio recording of the interview. Data analysis was undertaken using the NUDIST Power software, revision 4.0 .

The research consisted of 16 in-depth management interviews in five telecommunications-related organisations 
Table 1 Consolidated responses: Telecommunications companies and banks.

\begin{tabular}{ll}
\hline Issue mentioned by respondent & Response pattern \\
\hline Market pressures are forcing electronic business (EB) & 11 out of 26 interviews \\
EB as a new way of doing business & 12 out of 26 interviews \\
New processes needed to manage EB & 11 out of 26 interviews \\
Levels of success in implementing EB & 6 out of 26 interviews \\
Staff capabilities needed for EB & 7 out of 26 interviews \\
Speed to market through EB & 4 out of 26 interviews \\
Cost reduction/profit/revenue from EB & 3 out of 26 interviews \\
Customer impact & 3 out of 26 interviews \\
\hline
\end{tabular}

(including Telstra and Optus, the largest operators in Australia, and Clear,

Telecom NZ and EFSPOS from New Zealand). On the user side, ten in-depth interviews were conducted in the two largest Australian banks, Westpac and $\mathrm{NAB}$.

Interview prompt questions were focused first on issues external to each organisation in the general economy and secondly on issues inside the organisation. External and general probes included the following:

- Defining EB and EC

- Drivers of EB

- Inhibitors to the adoption and growth of EB

- Benefits of EB to society

- Costs of EB to society

- The impact of EB on the industry structure and dynamics

Internal issues included:

- The organisation's approach to EB

- The vision for EB

- Factors driving the move to EB

- Factors inhibiting the move to EB

- The effects of EB on the organisation

- The critical capabilities needed to meet EB objectives

- Extent of involvement in $\mathrm{EB}$

- Who is driving EB

The paper draws on the research findings from the second cohort of probes, which focused on the impact of ebusiness on the respondents' own organisations.

\section{EFFECTS OF EB ON THE ORGANISATION}

Two specific questions were asked; 'What are the effects of EB on your organisation?' and 'What other comments do you have on EB and how it relates to your organisation?' Open responses to these questions were recorded. The rationale for probing this topic was to better understand managers' perceptions of how developments in EB are affecting the structure and dynamics of an organisation; to identify important issues which impact on the efficiency and effectiveness of an organisation and different approaches to actioning EB direction; and to contrast different opinions of the how EB is impacting on organisations.

The consolidated responses of both telecommunications and bank senior managers to these open-ended questions are listed in Table 1 in order of frequency of response.

\section{Researchers' comments and observations}

When looking at the consolidated responses for both telecommunication companies and the banks, the three most critical issues were: seeing $\mathrm{EB}$ as a new way of doing business (mentioned in 12 
Table 2: Contrasting priority issues for telecommunications companies and banks

\begin{tabular}{lll}
\hline & Telecommunications companies & Banks \\
\hline 1 & Seeing EB as a new way of doing business & $\begin{array}{l}\text { Market pressures forcing companies to become } \\
\text { EB enabled }\end{array}$ \\
2 & New business processes needed to manage EB & $\begin{array}{l}\text { New business processes needed to manage EB } \\
\text { Need for changes to staff capabilities to handle }\end{array}$ \\
3 & Market pressures forcing companies to become & $\begin{array}{l}\text { EB successfully } \\
\text { EB enabled }\end{array}$ \\
Levels of success needed in implementing & $\begin{array}{l}\text { Need to share knowledge between people to } \\
\text { gain advantage }\end{array}$ \\
\hline
\end{tabular}

out of 26 combined responses); the need for new business processes to manage $\mathrm{EB}$ effectively (mentioned in 11 out of 26 combined responses); and that market pressures were forcing companies to become EB enabled (mentioned in 11 out of 26 combined responses).

In an effort to understand the different priority issues between telecommunications companies (telcos) and banks, Table 2 contrasts the leading issues in order of frequency of mention by respondents.

The notable difference between the two groups was that the banks felt the need for EB enablement through competitive pressures from other banks in the race to reduce operating costs and improve customer reach and service standards using emerging EB strategies. The telcos' primary focus was on $\mathrm{EB}$ as a new way of conducting business. There was agreement between telcos and banks on the second listed priority of developing new processes to manage EB.

Among the open-ended responses, some of the more significant issues included the following.

\section{Telcos}

Telcos mentioned the incentives to embrace EB, which included reductions in operating costs and, hence, enhanced profit margins and the opportunity to improve market reach and penetration by providing improved customer value. They also anticipated that the life of assets would be reduced as accelerated redundancies occur with the rapid changes in technologies supporting EB enablement.

In order to survive, then, companies had no choice other than to progressively and urgently follow an EB enablement path. The nature and pace of EB change is often set by key competitors in an industry.

It is usually difficult to assess the financial returns that $\mathrm{EB}$ projects will yield. This creates a problem in allocating funds between EB investments and other business investment opportunities where the returns can be assessed with greater certainty.

\section{Banks}

EB is seen to present the opportunity for greater transfer of knowledge between staff as they discuss implications of EB developments. It may change the structure and nature of the banking industry as competitors may emerge from non-traditional sources. The remarks above concerning the assessment of financial returns and allocating funds also apply here. There is a need for a change in staff skills in order to embrace EB effectively as well as a need for more middle management commitment in accepting and expediting EB change. Any fear of the unknown among executives in trying to come to terms with EB must also be overcome. 
Table 2: Classification of top three responses from Table 1

\begin{tabular}{ll}
\hline Category/motivation & Position in Table 1 \\
\hline Efficiency & $\mathrm{N} / \mathrm{a}$ \\
No response in this category & 2 \\
Effectiveness & 3 \\
EB as a new way of doing business & 1 \\
New processes needed to manage EB & 1 \\
Mxogenous & \\
\hline
\end{tabular}

$\mathrm{EB}$, electronic business.

Table 3: Classification of all responses in Table 1

\begin{tabular}{ll}
\hline Category/motivation & Position in Table 1 \\
\hline Efficiency & 7 \\
Cost reduction/profit/revenue from EB & 2 \\
Effectiveness & 3 \\
EB as a new way of doing business & 4 \\
New processes needed to manage EB & 5 \\
Levels of success in implementing EB & 6 \\
Staff capabilities for EB & 8 \\
Speed to market through EB & 1 \\
Customer impact & \\
Exogenous & \\
Market pressures forcing EB &
\end{tabular}

EB, electronic business.

The time to implement EB change is critical, as there is a competitive urgency.

\section{DIMENSIONS OF EFFECTIVENESS AND EFFICIENCY}

Incentives to use electronic channels may take the form of potential benefits in efficiency and effectiveness.

Economies in electronic communication and distribution transactions can substantially reduce costs of business operations. The richness of those connections is also enhanced with the potential for interactive, personalised and asymmetric relationships. There is also the ongoing potential to improve the reach to new supply sources and customers using the fast growing electronic network. ${ }^{8}$ In reality, most firms will need to plan marketing strategies for both traditional, or 'place', aspects of the business and the fast developing electronic or 'space' dimensions of the business (Rayport and Siviokla 1994). ${ }^{9}$ Both approaches need to be co-ordinated in a cost effective manner whilst providing the customer with an effective and integrated solution.

Some analysis was carried out in an attempt to examine the results in terms of primary motivation for adopting electronic business approaches. This was looked at in dimensions of efficiency and effectiveness.

Starting from basic definitions, the Concise Oxford English Dictionary ${ }^{10}$ defines 'effective' as 'having an effect'. In an attempt to add clarity to this meaning, 'effectual' is listed as 'answering its purpose'. For 'efficient', the dictionary provides 'productive of effort', while 'efficiency' is defined as 'the ratio of useful work performed to the total energy expended'. In a further attempt to add clarity to the definitions of effectiveness and efficiency, further definitions include: 'effective' — 'doing the 'right' things' and 'efficient' - 


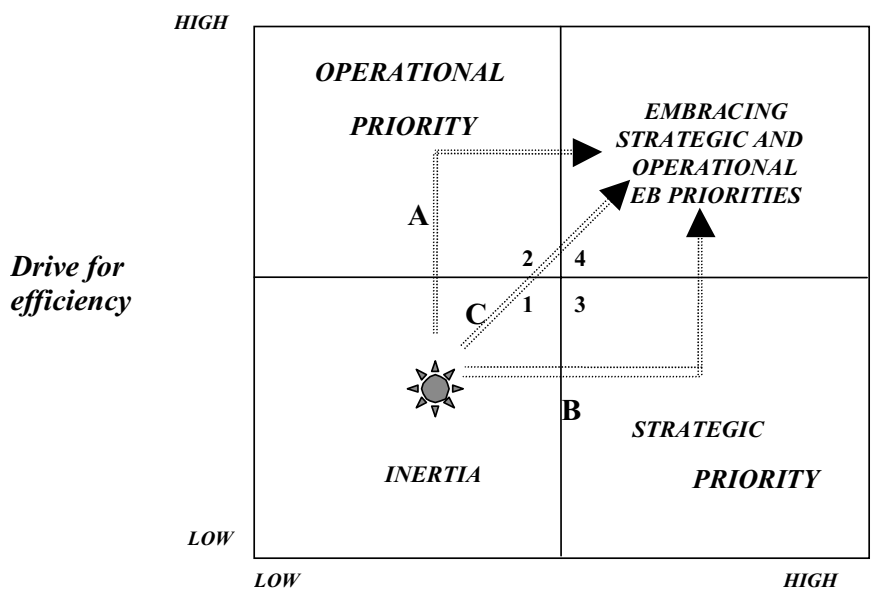

Drive for effectiveness

Figure 1: Electronic Business Enablement Matrix

'doing things right'.

If one makes the assumption that the above research responses could fall into one of three possible classifications in terms of motivation to adopt EB strategies or approaches - namely for purposes of efficiency, effectiveness or for reasons external or exogenous to the organisation - then the responses listed in Table 1 can be classified as shown in Tables 2 and 3 .

Table 2 classifies the top three responses in terms of the level of response of all 26 respondents (both banks and telcos). In practice, this means those that were mentioned by 11 or 12 of the 26 respondents.

Table 3 classifies all eight responses listed in Table 1.

From this analysis, it can be seen that the primary driving motivation for adopting EB strategies are related to improving the effectiveness of the business unit, ie doing things better or differently.

Another investigation showed the growing importance of effectiveness in attempting to assess marketing performance. The Chartered Institute of Marketing in the UK commissioned the
London Business School to examine the return on marketing expenditure in the financial services industry. In effect, they were invited to determine the efficiency of marketing expenditure in terms of the increased profits it contributed. They were not able to do so in the sample because of lack of data. The firms themselves could not do so either. What was found was effectiveness - by and large firms were achieving the targets in their plans. Competitive firms were winning because they were setting different targets (ie metrics). In the metrics project research they also found that management was increasingly assigning more importance to effectiveness rather than efficiency. ${ }^{11}$

\section{STRATEGIC IMPLICATIONS}

Managers who decide on EB enablement strategies in an organisation at a point in time, will be motivated by the opportunities it presents in terms of improving the business operation effectiveness, its efficiency or, perhaps, both. It has been suggested that actions concerned with effectiveness relate more to strategic moves, whilst those 
concerned with efficiency relate more to operational or tactical matters. ${ }^{12}$

To demonstrate alternate paths to a certain level of EB enablement at a point in time, it is useful to develop the EB Enablement Matrix shown in Figure 1. It has, as its axes, 'drive for effectiveness' and the 'drive for efficiency'. Quadrant positions on the matrix could be described as follows:

- EB inertia. Here, where the drive for efficiencies and effectiveness offered by EB enablement is relatively low, management decide not to make moves to be EB enabled as they see no benefits from either operating efficiencies or improved effectiveness.

- Operational priority. Managers placing their business units in this quadrant consider that the primary motivation for EB enablement will be because of the relatively high anticipated benefits through operating efficiencies.

- Strategic priority. Managers placing their business units in this quadrant consider that the primary motivation for EB enablement will be the relatively high benefits to the business unit's effectiveness.

- Embracing strategic and operational EB priorities. Managers placing their business units in this quadrant consider that the motivation for EB enablement will be the relatively high perceived benefits to both operating efficiency and improvements to the unit's effectiveness.

Assume that a business unit initially places itself at the point of the star in Figure 1. Here, managers have ranked the need for $\mathrm{EB}$ enablement low in terms of the estimated effectiveness and efficiencies that it could bring to the business unit. Managers may have reached this conclusion after carrying out an objective investigation of the potential advantages and disadvantages of becoming EB enabled using an evaluation tool similar to the Electronic Business Indicator Assessment. ${ }^{13}$ It has been observed that expanding the scope of ebusiness strategy is less effective when it requires large investment and when it threatens the existing business proposition. $^{14}$

The author's previous research among a sample of senior managers ${ }^{15}$ showed that the level of attraction, or forces driving organisations, to electronic business could be scaled according to importance in four key areas: cost benefits; competitive pressures; market advantage; and value adding.

- Cost benefits. This category relates to the incentive of reductions in operating and transaction costs of doing business electronically compared to traditional physical methods. Cost benefits transfer to improvements in operating efficiency.

- Competitive pressures. This category relates to a business unit's threat of being left behind in 'place' while others move to 'space'. Some companies have used electronic channels as a first mover marketing strategy.

- Market advantage. This category is when a business anticipates a strategic advantage such as market coverage, penetration, reach or customer access gained via electronic connections.

- Value adding. This is where electronic developments add value to customer satisfaction while building strong relationships. This may take the form of more comprehensive or more convenient on-line information both before and after the sale.

As in all evaluations, the benefits of 
moving into an electronic environment must be considered together with the potential inhibitors. Collectively, inhibitors will slow down or prevent the move towards electronic business involvement. Previous research has indicated that these would include the following considerations. ${ }^{16}$

- Legacies of the past. Those things that are not easily dispensed with practically, without great cost or political embarrassment. These may range from IT infrastructure to staff who do not have the skills or aptitude for the electronic way of doing business.

- Inability to access the technology and connectivity. These provide the electronic service to key markets, including the development of suitable payment systems for products and services supplied.

- Unable to afford or raise the capital funds necessary for EB development and expansion. Alternatively, decision makers not willing to allocate budgets adequate to complete EB projects.

- Customers may not want to do business electronically. They may prefer the benefits of traditional and personal face-to-face service.

Following such an investigation and evaluation, the business unit team could consider the alternative paths towards EB enablement in terms of the options shown in Figure 1.

\section{Path A}

Here, the path to an EB-enabled future is seen to occur through operational efficiencies. This approach infers that a future in EB can be justified mainly through cost savings. One example of this approach may be a retail bank that is motivated by the large reductions in the cost of marketing and delivering its services via EB channels compared to delivering them through a traditional branch property network.

\section{Path B}

In this case, the path to an EB-enabled future is seen to occur through the potential to build effectiveness by reaching suppliers and markets not previously accessible. ${ }^{17}$ One example of this approach could be that the managers of a retail bank see the opportunity to reach new market segments through electronic channels such as the internet, which could not be reached and serviced through the traditional branch property coverage.

\section{Path C}

Here, the path to an EB-enabled future is seen to occur through both the potential to build effectiveness and the potential to improve efficiency. This may involve a strong commitment with considerable resources devoted to a process of EB transformation, rather than a more gradual evolutionary path that could be inferred by making the move to EB enablement from an operational efficiencies path. ${ }^{18}$ To carry through the previous retail banking example, in this quadrant, managers are highly motivated by both the benefits of effectiveness and efficiency that EB enablement will bring to the business.

\section{IMPLICATIONS FOR MANAGEMENT}

In trying to bring about ebusiness transformation, companies have often paid too much attention to technology. Technology has driven the ebusiness enablement process; '.. as if adding the software or hardware could, on its own, bring about miracles. But systems do not 
work in a vacuum, and senior managers would do well to recognise the complementary nature of technology, business process and ebusiness readiness throughout the value chain, from their suppliers to their customers. By taking a more holistic view, executives can turn these facets of a company's operations into the drivers of ebusiness excellence. ${ }^{19}$

It has been suggested by other researchers that information technology and the internet have transformed the nature of business. This transformation is not only about conducting business on-line, but also about integrating ebusiness capabilities such as procurement and customer relationship management, into every aspect of value creation. ${ }^{20}$

Although technology is a key enabler of ebusiness, it is not an end in itself rather a path towards providing a business benefit. Very large IT budget allocations evident in the late 1990s were provided with the uncertainty of financial returns and business benefit out of fear of not being left behind in the ebusiness race. ${ }^{21}$ Now organisations are being more careful and budgets are under increased scrutiny. In supporting the move to ebusiness, executives are making sure the IT investments are based on a sound business case and benefits (Haapaniemi 2001). ${ }^{22}$

This exploratory research and the resulting prescriptive framework has attempted to add operational and strategic considerations to the debate and justification for devoting resources for the migration towards ebusiness enablement.

\section{Limitations of research}

Although the research provided some useful insights into the issues that managers contemplated in the race to become EB enabled, limitations of the research need to be acknowledged in reading the findings. These included the small sample of managers participating in the research and the fact that they were selected on the basis of their availability rather than on an objective sampling rationale. Another limitation was the small number and specific business nature of organisations taking part in the research, therefore substantially restricting the generalisability of any findings.

\section{References}

1 Rayport, J. F. and Jaworski, B. J. (2001) eCommerce, McGraw Hill/Irwin, Boston, MA.

2 Hartman, A. and Sifonis, J. (2000) Net Ready, McGraw Hill, New York, NY.

3 Lauden, C. and Traver, C. G. (2002) E-commerce, Addison Wesley, Boston, MA.

4 Lauden and Traver (2002) ibid.

5 Turban, E., King, D., Viehland, D. and Lee, J. (2006) Electronic Commerce 2006, Pearson Education International, Upper Saddle River, NJ.

6 Zwass, V, (2003) 'Electronic commerce and organizational innovation: Aspects and opportunities', International Journal of Electronic Commerce, Vol. 7, No 3, pp. 7-37.

7 Perrott, B. (2001) Organisational Considerations in Electronic Business Transformation, Working paper 5/01, School of Marketing, University of Technology, Sydney, Australia.

8 Evans, P. and Wurster, T. (2000) Blown to Bits, Harvard Business Press, Boston, MA.

9 Rayport, J. F. and Sviokla, J .J. (1994) 'Managing in the marketspace', Harvard Business Review, Vol. 72, November-December, pp. 141-150.

10 Fowler, H. W. and Fowler, F. G. (Eds) (1964) Concise Oxford Dictionary, Fifth Edition, Clarendon Press, Oxford, UK.

11 Ambler, T. (2000) Marketing and the Bottom Line, Financial Times Prentice Hall, London, UK.

12 Johnson, G., Scholes, K. and Whittington, R. (2005) Exploring Corporate Strategy, Pearson Education, Harlow, UK.

13 Perrott (2001) op. cit.

14 Turban et al. (2006) op. cit.

15 Perrott (2001) op. cit.

16 Perrott (2001) ibid.

17 Evans and Wurster (2000) op. cit.

18 Perrott (2001) op. cit.

19 Barua, A., Konana, P., Whinston, A. B. and Yin, F. (2001) 'Driving ebusiness excellence', $M I T$ Sloan Management Review, Vol. 43, No. 1, pp. 36-44.

20 Cavusgil, T. S. (2002), 'Extending the reach of ebusiness', Marketing Management, Vol. 11, No. 2, pp. 24-29.

21 Perrott (2001) op. cit.

22 Haapaniemi, P. (2001) 'The technology of transformation', Chief Executive, November, pp. 12-17. 